\title{
Discriminating drunkenness: A replication
}

\author{
WILLIAM W. BEATTY \\ North Dakota State University, Fargo, North Dakota
}

\begin{abstract}
Seventy-six students in an introductory psychopharmacology class watched a videotape that portrayed four adult males drinking at a poker game. The subjects were then asked to judge whether or not any or all of the players were legally drunk. In agreement with previous work, the accuracy of their judgments did not exceed chance.
\end{abstract}

Public laws in many jurisdictions in the United States now explicitly forbid operators and employees of retail liquor stores and taverns, as well as hosts of private parties, to serve alcohol to persons who are "intoxicated." Failure to comply with these so-called "dramshop laws" invites potentially expensive damage claims.

While few would disagree with the intention of these laws, the statutes implicitly or explicitly presume that accurate judgments of the state of intoxication of others can be made by virtually every adult in the society. Recently, Langenbucher and Nathan (1983) challenged this assumption. They asked 49 undergraduate social drinkers, 12 bartenders, and 30 police officers to make judgments of the state of intoxication and blood alcohol level (BAL) of confederates who had BALs of $0, .05$, or $.10 \%$. Regardless of whether the tests were conducted under laboratory or simulated field conditions, most subjects were unable to make accurate judgments. In fact, only 5 of the 91 subjects, all police officers, could judge the confederates' state of intoxication accurately. Four of these 5 raters were members of a special tactical unit whose mission was to apprehend drunken drivers. These 4 officers had received extensive training in the administration of tests to identify inebriates.

Since Langenbucher and Nathan's (1983) findings have important social and legal implications, the present systematic replication of their studies was performed.

\section{METHOD}

\section{Subjects}

The 76 subjects ( 40 males, 36 females) were students in an introductory psychopharmacology course, who participated in the study as part of a class demonstration. Their ages ranged from 18 to 43 years, but all but 4 of the subjects were 27 years old or younger. All subjects reported that they personally used alcohol and had previously observed drunkenness in others during their ordinary social experiences. Prior to the present study, the students had seen lectures and films about alcohol and

I thank Russ Glasgow, Mike Vasey, Kevin McCaul, Rex Bierley, and Bob Klesges, who assisted in making the videotape, and A. K. Chaturvedi, who lent the breathalyzer. My mailing address is: Department of Psychology, North Dakota State University, Fargo, ND 58105. had been assigned readings in their text. Nine of the subjects reported that they had worked in a job such as a bartending or cocktail waitressing that had required them to discriminate intoxication in others.

\section{Procedure}

In a medium-sized lecture hall (seating capacity $=130$ ) equipped with four wall-mounted monitors, the subjects were shown a 20-min videotape. that portrayed four white male college professors at what was described by the narrator as a typical "Saturday afternoon poker party." At the start of the tape, the narrator also explained the purpose of the demonstration and introduced the four poker players, who were shown in close-up. The narrator encouraged the subjects to remember the names of the players because at the end of the tape they would be asked to judge whether or not each of the players was "drunk." During the rest of the videotape, the subjects watched the players play several hands of seven-card stud. The four players sat around an ordinary card table. In addition to cards and poker chips, there were several empty beer bottles on the table.

The conversation among the players was spontaneous (i.e., unscripted) and consisted of the usual remarks associated with a card game. All players participated in the conversation to ensure that the subjects experienced an extensive sample of their verbal behavior. To ensure a clear sample of their motor behavior, all of the players got up and walked before the camera at least once during the videotape. The reasons for these movements, as explained by the players, were appropriate to the context (e.g., get food or drink, go to the bathroom, change the music on the stereo). About halfway through the tape, one of the players, who was "losing," suggested that the players change seats because his seat was unlucky. This switch provided an additional sample of the motor behavior of all subjects and also ensured that the subjects had frontal views of all four players.

Three of the players (K.M., B.K., and R.B.) were sober. R.B. and B.K. had consumed no alcohol in the preceding $24 \mathrm{~h}$ and did not drink alcohol during the filming. R.B. did consume water from a green beer bottle during the videotaping. B.K. did not drink during the videotaping, but he walked with a slight limp as the result of a minor knee injury. K.M. drank two beers during the filming but had consumed no other alcohol in the $24 \mathrm{~h}$ before filming. The last player, W.B., a 200-lb male, drank seven beers during the $1 \mathrm{~h}$ prior to filming and drank one more beer during the session. His BAL, as estimated with a breathalyzer (Alcohol Countermeasure Systems, Inc., Model J3A), exceeded $0.11 \%$ immediately before as well as just after the videotaping session. The other players registered BAL levels in the "safe" range on the same instrument.

At the end of the poker game, the videotape was stopped. The subjects were asked to judge whether each of the players was legally "drunk" (BAL of $.10 \%$ or greater) or "not drunk." They were told that any number of the players from 0 to 4 
might be intoxicated. Since their actual judgments spanned the full range of possibilities (i.e., all players "drunk" to all "not drunk"), this instruction was obviously credible. Just before the subjects made their ratings, the narrator reminded them of the identities of the four players. After the ratings were completed, the subjects were debriefed by showing them the videotapes of the actual tests made with the breathalyzer.

\section{RESULTS AND DISCUSSION}

If the subjects were simply guessing, 1 of 16 subjects should have correctly identified the state of drunkenness of all four players. That is, by chance alone, the expected number of people who would correctly respond on all four questions is slightly fewer than 5 of the present sample of 76 . In fact, only 1 subject accurately identified all four players with regard to their state of intoxication. This subject was not among the 9 who had worked as a bartender or cocktail waiter, but he spontaneously disclosed that he was a fourth-year pharmacy major who worked at the local VA hospital.

Table 1 presents a more detailed summary of the findings. There it can be seen that the single player who was actually intoxicated (W.B.) was judged to be "drunk" by fewer of the subjects than any of the other players. Furthermore, the subjects who had worked in jobs that required them to judge the sobriety of others were no more accurate in their judgments than the other subjects, who had had no such prior experience. However, the subjects in this subgroup were somewhat more likely to rate all players as "drunk." Thus, the present findings confirm the earlier work of Langenbucher and Nathan (1983).

In considering the implications of these findings in the naturalistic settings in which employees of drinking establishments and hosts of private parties are required to make judgments of the state of intoxication of their patrons, it is important to note that several features of the present situation should have fostered accurate discrimination of drunkenness by the experimental subjects. First, they had unobstructed views of relatively long samples of both motor and verbal behavior of all players at the card game. Second, they had to keep track of relevant information for only four "drinkers." Third, their attention was not diverted by the demands of making and serving drinks or of being a good host. Finally, the magnitude of the difference in BAL among
Table 1

Percentage of "Drunk" Judgments

\begin{tabular}{ccc}
\hline Player & All Subjects & $\begin{array}{c}\text { Bartenders/ } \\
\text { Waitresses only }\end{array}$ \\
\hline K.M. & 51.3 & 66.7 \\
B.K. & 51.3 & 77.7 \\
R.B. & 32.9 & 44.4 \\
W.B. & 30.2 & 44.4 \\
\hline
\end{tabular}

the four "drinkers" in the present study was larger than would exist in many naturalistic situations.

Considering how poorly our subjects performed, it seems unreasonable to assume that bartenders or cocktail waitresses could discriminate more accurately under the dark, noisy, and crowded conditions common in many bars and nightclubs. The same is probably true, although perhaps to a lesser extent, for hosts of private parties. Thus, the so-called dramshop laws, however well intentioned they may be, require judgments that far exceed the capacity of nearly everyone who has not had highly specialized training in judging intoxication.

Apparently the only way that a person without such training could accurately judge the level of inebriation in others would be to keep track of the number and the alcohol content of all drinks served to each patron in relation to their sex and body weight. But even if one makes the improbable assumption that bartenders, waitresses, and hosts of parties could and would keep track of such information accurately for all of their guests, dramshop laws would still not be reasonable because: (1) there is no practical way for the servers of alcoholic beverages to know whether the persons who order drinks are the ones who actually consume them, and (2) there is no reliable way for bartenders, waitresses, or hosts to know how much alcohol guests have consumed before they visit their establishments.

\section{REFERENCE}

Langenbucher, J. W., \& Nathan, P. E. (1983). Psychology, public policy, and the evidence for alcohol intoxication. American Psychologist, 38, 1070-1077.

(Manuscript received for publication May 4, 1984.) 